\title{
Working Strategies of Higher Vocational Teachers Under the Background of Post-Figurative Culture
}

\author{
Bi Zhi-li ${ }^{1, a^{*}}$, Wei Li-xia ${ }^{1, b}$, Liu Guang-yan ${ }^{1, c}$ \\ ${ }^{1}$ Academy of health, Binzhou Polytechnic, Binzhou, Shandong, China \\ $a^{*}$ beelili@126.com \\ bbzlxia@126.com \\ c86562811@qq.com
}

\begin{abstract}
This paper discusses the characteristics of students in higher vocational colleges under the background of post-figurative culture era, and requires teachers in higher vocational colleges to constantly improve their own quality and adopt diversified working strategies. Improvement methods include active learning of network application, various disciplines and students' major knowledge and so on. Summarize and disseminate work experience through curriculum construction; Write papers or undertake projects to improve performance. Work strategies include peer case guidance, introduction of successful experiences of celebrities, learning from nearby examples, innovation in student cadre work, and behavior therapy management of students who violate discipline.
\end{abstract}

Keywords: Post-figurative culture, higher vocational teachers, working strategies, ideological and political education in curriculum, Labor Education

\section{后喻文化背景下高职教师的工作策略}

\author{
毕智丽 ${ }^{1, a^{*}}$ 卫丽霞 ${ }^{1, b}$ 刘光艳 ${ }^{1, c}$
}

${ }^{1}$ 滨州职业学院健康学院, 滨州, 山东, 中国

$a^{*}$ beelili@126.com

${ }^{b}$ bzwlxia@126.com

c86562811@qq.com

\section{摘要}

本文论述了后喻文化时代背景下高职学生的特点, 要求高职教师不断提升自身素质, 采用多样化工作策略。提 升方式包括主动学习网络应用、各种学科、学生专业等知识; 通过课程建设来总结、传播工作经验; 撰写论文 或承担课题提升工作绩效。工作策略包括同龄人案例引导、名人成功经验介绍、学习身边的榜样、创新学生干 部工作，及行为疗法管理违纪学生等。

关键词: 后喻文化, 高职教师, 工作策略, 课程思政, 劳动教育

\section{1. 前言}

人类学家玛格丽特・米德将人类文化传递方式划 分为前喻文化、并喻文化和后喻文化，其中后喻文化 是长辈向晚辈学习, 由晚辈将知识文化传递给长辈的 文化传递方式。随着信息科技的极速发展, 当代大学 生与父辈、祖辈之间的 “文化反哺” 现象非常普遍,
当今社会的后喻文化时代特征便凸显出来 ${ }^{[1]}$ 。

当今时代, 网络已成为现代人生活环境中的必须 组成部分, 获取信息的便捷使教师向学生传授知识的 职能逐渐弱化, 教学相长的现象更趋普遍, “文化反 哺” 不只出现在家庭中的晚辈和长辈之间, 同样出现 在校园内的师生之间 ${ }^{[2]}$ 。特别是在大学阶段, 高校教 师面对已基本具备自主学习意识和能力的大学生, 课 
堂知识的吸引力越来越小，而教师个人的魅力、对知 识运用的方法、对待学生的态度等, 无不在潜移默化 中影响着学生“三观”的形成和他们对待学业的态度。

高等职业教育作为高等教育的重要组成部分, 接 纳的学生群体大多属于同龄群体中学习成绩较落后 的, 他们因为在成长过程中遭受了更多挫败, 形成了 逆反学习的心理习惯; 而当今时代物质条件的极大改 善, 又使他们缺乏抗挫能力的锻炼; 同时因为受到的 关注偏少, 他们更多选择网络虚拟世界来填补空虚, 受到多元文化的冲击, 严重的会导致价值观混乱 ${ }^{[3]}$ 。 总之, 高职学生的心智成熟程度不够理想。

\section{2. 时代要求高职教师能够自我提升}

一个人无论从事什么工作, 都不可能一成不变地 应对层出不穷的新问题、新任务。指导教师队伍建设 工作的纲领性文件《中共中央 国务院关于全面深化 新时代教师队伍建设改革的意见》发布之年, 正是 “00 后” 开始成为大学生主体之时, 新一代高职学 生对教师的需求有增无减。对于大多数高职学生来 说, 高职教师是他们在校期间以及未来人生路途中, 能够接触到的文化素质相对较高的群体, 高职教师们 的人格、心态、言语、行为等都非常容易且深远地影 响学生。《深化新时代职业教育 “双师型” 教师队伍 建设改革实施方案》中提到, 要 “建成一支师德高尚、 技艺精湛、专兼结合、充满活力的高素质 “双师型” 教师队伍”, 说明这是一项长期、艰苦、细致而富有 思想性、科学性、艺术性、知识性的工作, 需要高职 教师能够不断提升自身素质, 适应社会发展和学生成 才的需要。

\section{1 以身示范学习各种知识}

要给学生一杯水, 自己需先准备一桶水, 良好的 综合素质要以丰富的知识为基础。

首先, 高职教师应主动接触网络, 熟练应用教学 App、微信、小程序、QQ 群等工具, 一方面, 高职教 师可以利用这些途径撰写或转发一些学习资料, 及时 评价、回复或点赞学生发布的言论, 积极占领校园网 络阵地, 对高职学生的学习状态和学习效果进行及时 有效的掌握和引导; 另一方面, 通过网络和学生交流, 既可避免直接面对可能产生的尴尤, 又有利于高职教 师耐下心来倾听学生的问题, 弥补因课时限制导致师 生接触时间有限的情况。例如高职各专业普遍采用 “ $2+1$ ” 的人才培养模式, QQ 群、蘑菇钉等工具非常 适合第三年实习阶段的教学开展, 可以及时地上情下 达、下情上报, 还便于为学生传递招聘信息。

其次, 课程思政已成为教学改革的新方向, 广大 高职教师已热情参与其中, 这就要求老师们不但能讲 好学科内容, 同时也要做好学生的良师、益友、伯乐、 领导者、设计师、协调员、塑造者等多种角色, 他们 的政治素质、精神境界、学识水平、文明修养会直接 影响到高职学生世界观、人生观、价值观的形成, 所
以思政、教育学、心理学、社会学、管理学、哲学、 就业指导, 以及对文艺作品的鉴赏等知识都是高职教 师需要广泛涉猎的。

最后, 高职教师还应主动多了解所教学生的其他 专业知识, 因为学生心目中的好老师, 一定是能够将 任教课程与学生的专业充分结合的, 他们希望老师可 以对课程内容进行实践联系, 以便学生可以了解所学 知识的用武之地。对所教学生的专业、行业有一定的 了解, 还能够更有效地向学生传递职业发展情况, 帮 助学生做好学涯、职涯等生涯规划。高职层次对学生 知识掌握程度的要求是 “必需、够用”, 所以高职教 师对一些必要知识的了解具备现实可行性。

\section{2 课程建设利于总结传播}

高职教师在课程建设和教学实践中, 总结教学实 践经验, 可以将自己的相关学科知识更加系统化, 既 有利于自身教学水平的提高, 又有利于优秀教学经验 的传播。

吸引学生注意力、引发学生兴趣是开展教学实践 的关键, 这需要采用多样化的教学手段。高职学生学 习自觉性较差, 网络使用中娱乐所占比例较高, 高职 教师不妨结合授课内容, 向学生推荐好的游戏或者影 视作品, 主动用学生喜闻乐见的形式达到课程导入的 目的。学生可以从优秀的游戏设计或文艺作品中, 感 受到单纯说教难以表达的思想, 起到事半功倍的效 果; 还可以在讨论中向学生传达教师自己的理解, 进 行有针对性地教育引导。例如动画电影《霍顿与无名 氏》, 能在细节之处表达热爱生命、信任朋友、信守 承诺、子女教育、勇于接受新鲜事物、宽容敌人等重 大命题; 游戏 “生死关头谁先走?” ${ }^{[4]}$ 引导学生发现 自己和他人的价值, 思考人权、平等的真正意义, 危 急时刻如何从大处着眼做出选择和决策, 辩证分析问 题的方法, 以及在辩论中既诚恩表达自己的想法, 又 能有效倾听, 还能够说服他人的技巧。这些都是开展 课程思政的良好素材。

成功的教学效果能够实现学生取得进步, 同时也 能够提升授课教师的信心, 会更加促进师生在课堂上 的良性互动, 如此形成良性循环, 会使越来越多的学 生受益。

\section{3 论文、课题促进工作改善}

教学工作中有许多宝贵的经验, 可供教师相互借 鉴、相互促进提高, 高职教师需要用论文发表或承担 课题的方式进行总结、反思, 并提升自己的职业绩效。 研究的过程同样可以与对学生的引导结合起来, 例如 由学生参与协助开展调查研究, 从问卷设计、调查开 展, 到数据分析、结论总结等工作, 高职教师可以通 过对学生进行全程引导, 教师收获学术成果, 学生也 会在参与、了解的基础上对研究工作产生一定的兴 趣, 有利于学生未来的职业发展。 
身教重于言传, 高职教师以身示范, 在主动学习、 研究的过程中表现出来的积极情绪, 和在收获知识或 研究成果时表达出来的喜悦, 都可以感染学生, 使学 生了解学习和研究虽有枯燥, 但努力之后获得好的结 果, 能够满足人 “自我实现” 这个最高层次的需要。 这对于营造良好的学习和研究氛围多有助益。

\section{3. 多样化工作策略积极引导学生}

教师都希望能够通过自己的工作，全方位地带给 学生良好的影响, 但传统的授课方式只能满足知识和 技能的传授, 不能满足青年学生奔放跳跃的多样需 求, 这就要求教师能够采取更多样化的引导策略。

\section{1 用同龄人案例感染学生}

在学业、就业, 甚至生活、情感等问题上, 同龄 人的事例对高职学生最具有借鉴意义, 因此, 高职教 师采用案例引导式的学生思想工作方法, 往往效果更 佳。例如在学生萌发退学念头, 或后悔选错专业等情 况出现的时候, 往届学生中对专业不满曾想退学, 又 在家人劝说下恢复学业, 后来对口就业的案例, 或放 弃学业而发展受限的案例, 可以提醒学生如何做出对 自己和家人负责的选择; 当学生就业受挫, 怀疑社会 不公的时候, 在相同的工作岗位上, 社会家庭背景相 似, 而工作成绩不同的学生案例, 可以使学生意识到 自身能力、素质、情商才是成功的关键, 从而起到勉 励学生奋发图强, 努力提高自身竞争力的作用; 高职 学生年轻气盛, 遇事易急躁, 自我中心不懂谦让, 一 名心态端正、办事公正、同学信任的学生, 在名额紧 张主动放弃申请助学金后, 却因为出色的学生干部工 作获得了额外资助, 她平静的一句话 “这也就是所谓 的好人有好报吧!”能够向后来的学生们传递无尽的 正能量。

\section{2 名人轶事指引成长方向}

高职教师通过关注社会热点, 了解文化现象, 借 名人的社会影响力, 宣传主流文化认可的价值观, 更 易于学生接受, 符合高职学生的认知水平。例如文体 明星、企业家的成功故事, 有教养、有风度社会名流 的思想、做派, 甚至深入人心的文学作品中主要角色 的亮点描述, 都是学生可以模仿的对象。例如 “魔术 活字典” 刘谦并不是 “天才”, 他的成功是有准备和 可以借鉴的, 是兴趣爱好、刻苦锻炼、博览群书、多 学科融会贯通, 以及自身的综合素质和敬业精神成就 了他; 在英国, 凯特与威廉王子的爱情故事家喻户晓、 令人艳羡, 与早逝的戴安娜王妃相比, 她是一个更有 才华、更加智慧、更懂得如何获得自己想要的幸福的 优秀女人, 是每一位女性应该学习的榜样; 职场强人 杜拉拉说: “一个人一生吃的苦是个常数。如果当学 生时、年轻时不吃苦, 以后有的是苦头吃。如果现在 努力刻苦, 不怕吃苦, 以后会过得很幸福。”

\section{3 身边榜样引发比学赶超}

榜样的示范作用力量巨大, 尤其是身边的榜样, 周围环境中的良好风尚, 往往对个人产生深远的影 响。找到优秀学生各不相同的长处, 树立各种典型, 使同学们了解他们的做法, 并学习运用到自己的生涯 中, 比学赶超的大环境能够整体提高学生素质。例如 对享受助学金学生的自强案例进行提炼传播, 使身残 志坚珍惜求学机会、打工减轻贫困家庭负担、兼顾家 中老幼坚持上学、学业与学生干部工作双优秀等突出 事迹, 有机会影响更多学生, 让大家懂得感恩、树立 责任感、珍惜已拥有的, 学会要想获得希望拥有的东 西, 就需要付之于实际行动, 做关怀他人、服务社会、 忠于祖国、道德高尚的有用之才。另外, 高职教师平 时为人处事以身作则, 面对困境心态积极, 乐观向上 有求知欲, 同样可以成为学生们身边的榜样。

\section{4 积极拓展创新班委职能}

班委一般由较优秀的学生担任, 班委的工作一方 面可以服务老师和同学, 另一方面也可以得到自身锻 炼。一个古板守旧的班委团体, 与一个不断创新的班 委团体, 营造出的班级气氛, 带领同学们渡过的大学 校园生活, 会有很大的不同, 因此高职教师应引导学 生干部既要用心去做日常工作, 又要有创新意识, 使 他们充分发挥自己的聪明才智, 让他们的能力得到最 充分的施展和锻炼。例如授课教师接触最多的是学习 委员, 一般是由认真负责、耐心细致、成绩较好的学 生担任, 做到及时上传下达即算称职。如果授课教师 引导学习委员及时了解同学们的学习困难并反馈给 授课教师, 还能积极组织各种活动调动同学们的学习 积极性、提升学习效果, 使大家在良性竞争的氛围中 互相勉励、互相帮助、共同进步，这就可以成为一位 优秀的学习委员了。另外, 看似与教学工作无关的心 理健康委员, 有的是性格开朗、有热情, 像 “开心果” 般的外向学生, 有的是心细如发、体察入微的内向学 生, 都可以通过发挥他们的性格特长, 服务于同学们 的学习活动, 他们或能及时发现同学中出现的学习困 难等心理问题, 或能感染大家积极阳光地应对学业发 展。高职教师需要配合学生管理人员对学生干部的工 作积极性进行调动, 使他们意识到为老师和同学们服 务是一件快乐的事情, 同时自己的能力也得到了提 升, 求学阶段不要吝惜付出, 因为有付出才有收获, 重要的是自己得到了宝贵的人生财富。

\section{5 行为疗法改善问题行为}

违纪学生的教育引导也是高职教师日常工作的 组成部分, 一点不经意的急躁就可能毁掉师生之间长 时间建立起来的信任, 因此 “爱之深, 责之切” 不是 好的教育方式。运用 “行为疗法” 的理念, 对违纪学 生实施适当的惩罚, 可以起到消除违纪行为, 建立良 好习惯的效果 ${ }^{[5]}$ 。例如让违纪学生付出一定的体力劳 动, 帮忙跑腿送材料、打扫教师办公室等; 或是脑力 劳动, 帮教师完成一些资料整理、文本录入的工作, 
也可以算是对学生实施了劳动教育 ${ }^{[6]}$ 。学生的收获首 先是劳动本身带来的, 劳动使人快乐, 使人有成就感; 其次学生的劳动使高职教师有机会更深入地了解他 们, 体力劳动时的表现, 或完成文本的质量, 都反映 了学生的某些特点, 有利于日后有针对性地教育引 导; 最后, 学生也因此更加了解老师的工作, 从而更 加理解、体谅老师，促进师生感情的发展。

\section{4. 结语}

高职教师工作是培养社会主义合格建设者和可 靠接班人的神圣工作, 铸造人类 “灵魂” 的工程师, 欲铸人 “魂”, 必先铸己 “魂”, 在后喻文化的当今时 代, 能否赢得学生的尊重和爱戴, 在学生心目中形成 长期影响, 需要高职教师不断提升自身素养, 积极将 课程建设和论文、课题等成果进行提炼总结, 在主动 学习方面成为学生的榜样。同时, 面对比自己更加适 应后喻文化且已经成年的这一代高职学生, 高职教师 更应注重对身边的和经典的教育素材进行积累, 在教 育实践中还要因材施教, 多样化的工作策略才能有效 应对多样化的学生需求。

\section{项目基金}

本文为以下基金项目的阶段性成果：1. 滨州职业 学院科研项目《性别差异对高职生职业认同感影响及 对策的分析研究——以护理专业为例》(编号: 2017YJKT12), 主持人：毕智丽; 2. 山东省高等学校 科研计划项目《内部 EAP 在高职教师心理维护中的应 用研究》(编号: J12WH106), 主持人: 胡云斗; 3 . 滨州职业学院教学改革研究项目《“学分+学点、动态 项目、多维同步、平台支撑” 新时代 “青马工程” 培 训班课程体系构建研究》(编号: xy jg2122), 主持人: 谢根坦; 4. 滨州职业学院科研项目《新时代高职劳动 教育综合干预与质量监测研究》(编号: 2020YJKT36), 主持人：谢根坦。

\section{作者简介：}

毕智丽 (1979-)，女，河北沧州人，副教授。国 家二级心理咨询师、二级公共营养师、滨州市总工会 心理服务专家团成员, 华东师范大学访问学者, 研究 方向为职业教育教师教育与课程改革。

\section{REFERENCES}

[1] Lin F. (2020) The Subject of Ideological and Political Education from the Perspective of Post-yu Culture and Its Value Relationship. Future and Development, 44(01): 92-95.

[2] Liu H.S. (2014) The influence of we media on College Students' Ideological and political education and Its Countermeasures. People's Tribune, 429: 152-153.

[3] Zhang N. N. (2014) On the Countermeasures of College Ideological and Political Education in Post Figurative Culture. Education and Teaching Research, 28(1): 66-68,72

[4] Zhang Z. (2011) Vocational College Students' employment and entrepreneurship guidance. Beijing Normal University Press, Beijing.

[5] Guo N. F. (2012) Psychological counselor (Level 3). Nationalities Publishing House. Revised edition, Beijing.

[6] Tan, C. B. (2019) Understanding the concept of labor education: how to understand the basic connotation and characteristics of labor education. Journal of the Chinese Society of Education, (02):82-84. 